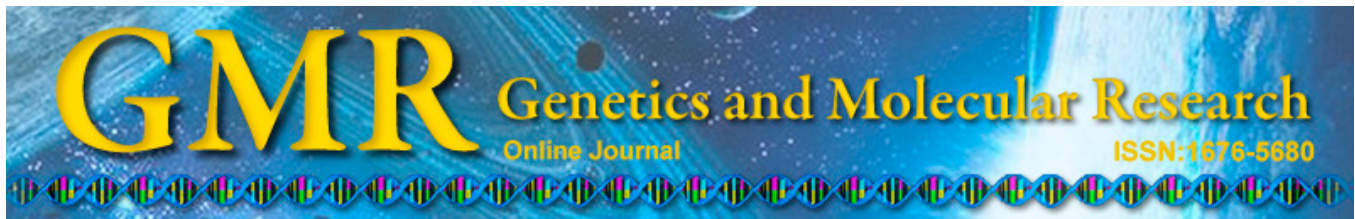

\title{
Role of MshQ in MSHA pili biosynthesis and biofilm formation of Aeromonas hydrophila
}

\author{
Y.X. Qin ${ }^{1,2}$, Q.P. Yan $^{1,2}$, X.X. Mao ${ }^{1,2}$, Z. Chen ${ }^{1,2}$ and Y.Q. $\mathrm{Su}^{3}$ \\ ${ }^{1}$ Fisheries College, Jimei University, Xiamen, Fujian, China \\ ${ }^{2}$ Key Laboratory of Healthy Mariculture for the East China Sea, \\ Ministry of Agriculture, Jimei University, Xiamen, Fujian, China \\ ${ }^{3}$ College of Ocean and Earth Science, Xiamen University, Xiamen, Fujian, China \\ Corresponding author: Q.P. Yan \\ E-mail: yanqp@jmu.edu.cn
}

Genet. Mol. Res. 13 (4): 8982-8996 (2014)

Received January 9, 2014

Accepted May 13, 2014

Published October 31, 2014

DOI http://dx.doi.org/10.4238/2014.October.31.13

\begin{abstract}
Biofilm formation of pathogen bacterium is currently one of the most widely studied topics; however, little is known regarding pathogen bacteria biofilms in aquaculture. Aeromonas hydrophila is a representative species of the genus Aeromonas, which has been recognized as a common pathogen, is associated with many diseases in aquatic animals, and causes significant mortality. The objectives of this study are i) to confirm that $A$. hydrophila can form biofilms on abiotic substrates and construct a biofilm growth curve for this bacterium; ii) to identify the genes that play crucial roles in A. hydrophila biofilm formation. The biofilm growth curve of $A$. hydrophila was constructed using a crystal violet assay, which showed that biofilm formation for this bacterium is a dynamic process. Next, a mutant library of pathogenic A. hydrophila B11 was constructed using the mini-Tn 10 transposon mutagenesis system. A total of 861 mutants were screened, and 5 mutants were stably deficient in biofilm formation. Molecular analysis of the mutant $\mathrm{B} 112$ revealed that the open reading frame that encodes the protein MshQ was disrupted. Comparison of biological characteristics including growth, motility, and adhesion between the
\end{abstract}


mutant B112 and the wild-type strain B11 suggested that MshQ is necessary for mannose-sensitive hemagglutinin pilus biosynthesis of A. hydrophila, and that these pili play crucial roles in A.hydrophila adherence to a solid surface during the early stages of biofilm formation.

Key words: Biofilm; Aeromonas hydrophila; MshQ; Pilus; Transposon; MSHA pili

\section{INTRODUCTION}

Most microbes in the natural environment live in surface-associated communities referred to as biofilms (Costerton et al., 1995; Schwartz et al., 2012). Bacteria in biofilms are markedly different from their planktonic counterparts. One of the prominent characteristics of biofilm bacteria is that cells grow in multicellular aggregates encased in an extracellular matrix produced by the bacteria (Hall-Stoodley and Stoodley, 2009; Irie et al., 2012). Extracellular matrices protect constituent cells from external aggression and act as a diffusion barrier to small molecules, resulting in a bacterial community in which some of the cells are metabolically inactive (Hall-Stoodley and Stoodley, 2009; López et al., 2011). Sessile biofilm communities can also give rise to nonsessile individuals that can rapidly multiply and disperse. Therefore, biofilms can not only protect bacteria from host-defense mechanisms including phagocytosis but also serve as a recalcitrant source of bacteria during antimicrobial therapy (Hall-Stoodley and Stoodley, 2009; Moscoso et al., 2009). Ojha et al. (2008) found that Mycobacterium tuberculosis biofilms have a high proportion of cells $(\sim 10 \%)$ that survive isoniazid treatment, even at concentrations $(10 \mathrm{mg} / \mathrm{mL})$ much higher than the minimal inhibitory concentration (MIC) $(\sim 0.1 \mathrm{mg} / \mathrm{mL})$. Thus, it is not surprising that a large number of chronic bacterial infections involving bacterial biofilms are not easily eradicated by conventional antibiotic therapy. For these reasons, formation of biofilm has been recognized as an important mechanism of virulence in many pathogenic bacteria (Costerton et al., 1999; López et al., 2011). In the developed world, more than $60 \%$ of bacterial infections currently treated by physicians are thought to involve biofilm formation (Costerton et al., 1999).

Over the last 10 years, recognition of microbial biofilms has become a highly significant topic in microbiology that is relevant to several important sectors of modern society. Some important pathogenic bacteria such as Escherichia coli, Pseudomonas aeruginosa, and Staphylococcus aureus, among others, are well-studied model systems of organisms that form biofilms. The developmental stages, structural components, and even the molecular mechanisms regulating biofilm formation of these bacteria are well-understood (López et al., 2011). O'Toole and Kolter (1998) found the ClpP protein (a component of the cytoplasmic Clp protease) participates in biofilm formation in P. fluorescens. Studies on Vibrio cholerae, Aeromonas species, and Shewanella oneidensis suggested that flagella and mannose-sensitive hemagglutinin (MSHA) pili contribute to biofilm formation (Watnick and Kolter, 1999; EnosBerlage et al., 2005; Saville et al., 2010).

Although some features are recognized as general attributes of biofilm formation, the mechanisms that bacteria employ to form biofilms vary weldly among different species, and even vary between different strains of the same species. Genes that are predicted to play significant roles in biofilm development have not been identified (Monds and O'Toole, 2009; López et al., 2011). 
In contrast to several studies examing bacteria biofilm in the clinic, few researchers have realized the importance of bacterial bioflims in aquaculture; moreover, most of these reports are focused primarily on environmental bacteria. The limited reports on the biofilm of pathogenic bacteria found that major bacterial fish pathogens such as Vibrio harveyi, $V$. parahaemolyticus, and Aeromonas hydrophila can form biofilms on abiotic substrates (Ringø et al., 2010), and these biofilm bacteria in aquaculture are also not easily eliminated by antimicrobials and sanitizer treatment (Karunasagar et al., 1996). Furthermore, the biofilm of the fish pathogen Flavobacterium columnare has been confirmed to display potential virulence to channel catfish when compromised skin is exposed to the mature biofilm of $F$. columnare (Cai et al., 2013). All previous studies have suggested that pathogen biofilms may be a source of iterative and continual infections of aquaculture animals. However, there are no reports on the molecular mechanisms of biofilm formation of pathogenic bacteria in aquaculture.

Aeromonas hydrophila is a representative species of the genus Aeromonas and is found in water, water habitants, domestic animals, and foods. It is not only a common pathogen involved in heavy mortalities in aquaculture animals (van der Marel et al., 2008; Jiravanichpaisal et al., 2009), but also a causative agent of gastrointestinal and extraintestinal infections in humans (AguileraArreola et al., 2005). However, little is known regarding the biofilm of $A$. hydrophila, particularly its mechanism of biofilm formation. In this study, a biofilm model of $A$. hydrophila on abiotic substrates was established and the mechanism of biofilm formation was also investigated. This study is the first report of the mechanism of pathogenic bacteria biofilm formation in aquaculture.

\section{MATERIAL AND METHODS}

\section{Bacterial strains and growth conditions}

Bacterial strains and plasmids used in this study are listed in Table 1. Escherichia coli were grown at $37^{\circ} \mathrm{C}$ in LB, and A. hydrophila were grown at $28^{\circ} \mathrm{C}$ in trypticase soy agar (TSA). The media were supplemented with the appropriate antibiotics at the following concentrations: $100 \mu \mathrm{g} / \mathrm{mL}$ kanamycin (Km); $50 \mu \mathrm{g} / \mathrm{mL}$ ampicillin (Ap), and $50 \mu \mathrm{g} / \mathrm{mL}$ streptomycin (Sm).

\begin{tabular}{|c|c|c|}
\hline Strain or plasmid & Characteristic(s) & Source or reference \\
\hline \multicolumn{3}{|l|}{$\begin{array}{c}\text { Strains } \\
\end{array}$} \\
\hline \multicolumn{3}{|c|}{ Aeromonas hydrophila } \\
\hline B11 & Wild-type strain $\left(\mathrm{Sm}^{\mathrm{R}}\right)$ & Guo, 2006 \\
\hline B111-B115 & Mini-Tn $10 \mathrm{Km}$ insertion mutant deficient in biofilm formation $\left(\mathrm{Sm}^{\mathrm{R}} \mathrm{Km}^{\mathrm{R}}\right)$ & This study \\
\hline B112 & $m s h Q$ of B11 inactivated by insertion of a mini - Tn $10 \mathrm{Km}$ & This study \\
\hline \multicolumn{3}{|l|}{ Escherichia coli } \\
\hline SM10 & thi thr leu tonA lacY supE recA $\mathrm{RP} 4-2-\mathrm{Tc}:: \mathrm{Mu}: \mathrm{Km}(\lambda$ pir $)$ & Herrero et al., 1990 \\
\hline E.coli $\mathrm{DH} 5 \alpha$ & $\begin{array}{l}\mathrm{F}^{-}, \varphi 80 \mathrm{~d} l a c Z \Delta \mathrm{M} 15, \Delta(\operatorname{lac} Z Y A-\arg F) \mathrm{U} 169, \text { deoR, recAl endA1, } \\
\quad h s d R 17\left(r K^{*}, m K^{+}\right), \text {phoA, supE44, } \lambda, \text { thi }-1, \text { gyrA96, relA1 }\end{array}$ & Takara \\
\hline \multicolumn{3}{|c|}{ 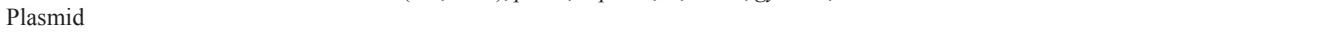 } \\
\hline pMD18-T & Cloning vector, $\mathrm{Amp}^{\mathrm{r}}$ & Takara \\
\hline $\mathrm{pLOF} / \mathrm{Km}$ & $\mathrm{Ap}^{\mathrm{R}}$; Tnl0-based delivery plasmid with $\mathrm{Km}^{\mathrm{R}}$ & Herrero et al., 1990 \\
\hline
\end{tabular}

\section{Biofilm formation assay and biofilm growth curve}

Biofilm formation was performed using a modified procedure of Enos-Berlage et al. 
(2005). Overnight cultures were diluted 1:100 into fresh trypticase soy broth (TSB). Next, 200 $\mu \mathrm{L}$ aliquots were added to 96-well microtiter plates, and the plates were incubated without agitation at $28^{\circ} \mathrm{C}$ in humidified conditions for $24 \mathrm{~h}$. The wells were washed 3 times with 250 $\mu \mathrm{L}$ of sterile phosphate-buffered saline (PBS) to remove any non-adhering bacteria. Surfaceattached cells were stained with $200 \mu \mathrm{L}$ of a $0.5 \% \mathrm{CV}$ solution for $5 \mathrm{~min}$ and washed 3 times with PBS. CV-stained biofilms were solubilized in $200 \mu \mathrm{L}$ of $95 \%$ ethanol, and the absorbance was determined using a plate reader at $590 \mathrm{~nm}$. The readings were corrected using a reading obtained from $200 \mu \mathrm{L}$ of fresh TSB without bacteria. When the biofilm growth curve was drawn, 12 wells were removed after incubation for $0,2,4,6,8,10,12,14,16,18,24,36,48$, and $60 \mathrm{~h}$.

\section{Mutagenesis of $A$. hydrophila strain B11 and isolation of mutants defective in biofilm formation}

The mini-Tn $10 \mathrm{Km}$ transposon was introduced into the A. hydrophila strain B11 on the suicide vector pLOFKm carried by E.coli Sm10 through a filter mating technique developed by Herrero et al. (1990) with minor modifications. Briefly, $0.22-\mu \mathrm{m}$ filters with a 1:4 mixture of the donor strain, E. coli Sm10 (pLOFKm) carrying the mini-Tn $10 \mathrm{Km}$, and the recipient strain A. hydrophila B11, were incubated for $4 \mathrm{~h}$ at $28^{\circ} \mathrm{C}$ on TSA plates supplemented with $3 \mathrm{mM}$ isopropyl $\beta$-D-1-thiogalacto-pyranoside (IPTG). Filters were transferred into Eppendorf tubes containing $1 \mathrm{~mL}$ TSB and vortexed. Next, $100 \mu \mathrm{L}$ suspension was spread on TSA plates supplemented with $\mathrm{Km}^{100}$ and $\mathrm{Sm}^{50}$ to select for $A$. hydrophila strains carrying the mini$\mathrm{Tn} 10 \mathrm{Km}$ transposon. Following incubation at $28^{\circ} \mathrm{C}$ for $24 \mathrm{~h}$, single colonies were selected for analysis of biofilm formation using the method described above. The colony producing the lowest amount of biofilm was used for further study.

\section{Southern analysis}

Southern blotting was performed according to the procedure described by Rock and Nelson (2006) with some modifications. Briefly, total genomic DNA was extracted from $A$. hydrophila B11 and the biofilm formation-deficient mutants using a bacterial genomic DNA extraction kit (Takara; Shiga, Japan). Genomic DNA was digested with the SacI (Takara) restriction endonucleases, which does not cut within the transposon, and electrophoresed on $0.8 \%$ agarose gel in Tris-acetate-ethylenediaminetetraacetic acid (EDTA) (TAE) buffer. The DNA was transferred to a nylon membrane using the Turboblotter system according to the instructions of the manufacturer. Blots were probed with a digoxigenin (DIG)-dUTP-labeled probe (Roche) for the mini- $\mathrm{Tn} 10 \mathrm{Km}$. The $\mathrm{Km}^{\mathrm{R}}$ gene probe was created by polymerase chain reaction (PCR) amplification of a 176-base pair (bp) region of the $\mathrm{Km}^{\mathrm{R}}$ gene using primers $\mathrm{Km} 3$ (5'-CGGGGATCGCAGTGG-3') and Km4 (5'-TGGGAAGCCCGATGC-3') and the DIG-PCR probe synthesis kit (Roche; Mannheim, Germany). After hybridization at $42^{\circ} \mathrm{C}$ for $16 \mathrm{~h}$, the membrane was washed and immunological detection was observed using the DIG Detection Kit (Roche). We expected to detect single bands for mutants with a single transposon insertion.

\section{Molecular analysis of the mutants}

DNA sequences flanking transposon mutants were determined using thermal asymmetric interlaced polymerase chain reaction (TAIL-PCR). An arbitrary primer was supplied 
with the Genomic walking kit (Takara), and the nested primers specific to the transposon are listed in Table 2. Among the nested primers, LSP4, LSP5, and LSP6 were used to amplify upstream sequences flanking the transposon, and RSP4, RSP5, and RSP6 were used to amplify downstream sequences flanking the transposon. TAIL-PCR products were purified using a Gel Extraction Kit (Omega; Norcross, GA, USA), cloned into the pMD18-T vector (Takara), and sequenced. DNA sequences were analyzed using BLASTN and other software.

\begin{tabular}{ll}
\multicolumn{2}{c}{ Table 2. Specific primers used in TAIL-PCR. } \\
\hline Primer & \\
\hline LSP4 & Sequence \\
LSP5 & 5'-ATGCTTGATGGTCGGAAGAGGC-3' \\
LSP6 & 5'-CATCGGGCTTCCCATACAATCG-3' \\
RSP4 & 5'-ATTATCGCGAGCCCATTTATACCC-3' \\
RSP5 & 5'-CCTGTTGAACAAGTCTGGAAAGAAATG-3' \\
RSP6 & 5'-GATCTTGCCATCCTATGGAACTG-3' \\
\hline
\end{tabular}

\section{Transmission electron microscopy}

Bacterial cells were grown on TSA plates for $16 \mathrm{~h}$ and colonies were gently resuspended in PBS. Next, the bacterial suspensions were placed on Formvar-coated grids and negative-stained with $2 \%$ acetate. The preparations were observed using a Tecnai F20 (Philips; Hillsboro, OR, USA) transmission electron microscope.

\section{Bacterial growth profiles}

The growth profiles of the strains were determined by inoculating $50 \mu \mathrm{L}$ of a TSB bacterial culture grown for $18 \mathrm{~h}$ into the wells of a sterile 96 -well microtiter plate containing $250 \mu \mathrm{L} \mathrm{TSB}$. The plate was incubated at $28^{\circ} \mathrm{C}$ and the optical densities (OD) at $550 \mathrm{~nm}$ of each well were recorded hourly until $30 \mathrm{~h}$. Each culture was inoculated in triplicate and the values of $\mathrm{OD}_{550}$ were averaged (Vine et al., 2004).

\section{Test of bacterial motility}

Single bacterial colonies were inoculated into test tubes filled with semi-soft medium and incubated at $28^{\circ} \mathrm{C}$ for $72 \mathrm{~h}$ to test motility.

\section{Adhesion assay}

An adhesion assay was performed as described by Balebona et al. (1995) with some modifications. Bacteria suspensions were adjusted to an $\mathrm{OD}_{550}$ of $0.30\left(10^{8}\right.$ colony-forming units $/ \mathrm{mL}$ ) in PBS. Bacterial suspensions were placed on Petri dishes containing clean glass slides and incubated in a humidity chamber at $28^{\circ} \mathrm{C}$ for $1 \mathrm{~h}$. Next, the slides were washed thoroughly by dipping several times in beakers containing $500 \mathrm{~mL}$ PBS and air-dried at $28^{\circ} \mathrm{C}$ for $20 \mathrm{~min}$, fixed with absolute methyl alcohol at $28^{\circ} \mathrm{C}$ for $20 \mathrm{~min}$, stained with crystal violet for 2 min, and washed and air-dried. The slides were then examined under a light microscope. The average number of bacteria adhering to $1 \mathrm{~mm}^{2}$ of the glass surface was determined. For each 
assay, $101-\mathrm{mm}^{2}$ areas were counted and the average value was calculated.

\section{Statistical analysis}

All data were statistically analyzed using analysis of variance tests in SPSS (SPSS, Inc.; Chicago, IL, USA).

\section{RESULTS}

\section{Biofilm growth curve}

The biofilm growth curve of $A$. hydrophila B11 showed that biofilm formation of this strain is a dynamic process (Figure 1). Biofilm development and dispersion were alternately present during the $60 \mathrm{~h}$ of continuous incubation. Initially, the $\mathrm{OD}_{590}$ values continued to increase and reached the first peak value after $8 \mathrm{~h}$ of incubation. After $8 \mathrm{~h}$, the $\mathrm{OD}_{590}$ values began to decrease and reached a minimum after $14 \mathrm{~h}$ incubation. When the incubation time reached $24 \mathrm{~h}$, the $\mathrm{OD}_{590}$ values reached a second maximum value and then reduced again with increasing incubation time.

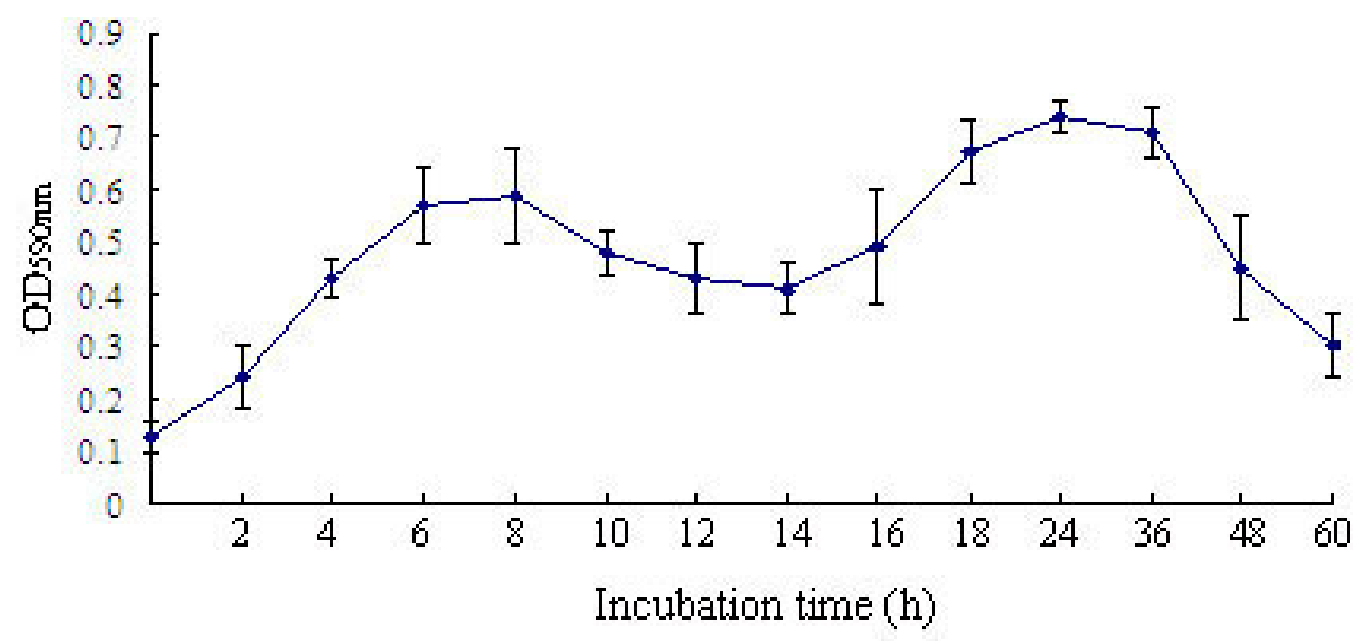

Figure 1. Biofilm growth curve of Aeromonas hydrophila B11.

\section{Isolation of mutants defective in biofilm formation}

Mutagenesis was performed using the mini-Tn $10 \mathrm{Km}$, which was introduced into $A$. hydrophila $\mathrm{B} 11$ on a suicide plasmid pLOFKm. Transposants were selected on TSA containing $100 \mu \mathrm{g} / \mathrm{mL} \mathrm{Km}$ and $50 \mu \mathrm{g} / \mathrm{mL} \mathrm{Sm}$. Of 861 individual colonies screened, 13 mutants formed significantly weak biofilms at the first screening when compared with the wild-type strain $(\mathrm{P}<0.05)$. Five mutants were stably deficient in biofilm formation after three screenings (Figure 2), and the other 8 mutants exhibited a reversion to biofilm formation (data not 
shown). Biofilm formation-defective mutants were designated as B111 to B115. Among the 5 mutants, the B112 strain produced the lowest amount of biofilm $(\mathrm{P}<0.05)$ and was selected for further study.

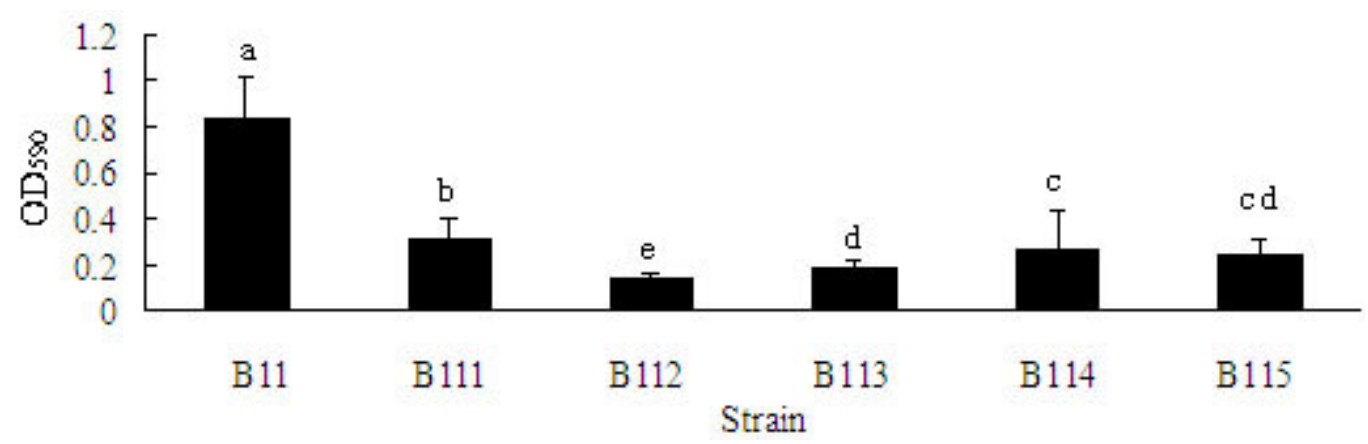

Figure 2. Biofilm formation of the wild-type strain B11 and the mutants. Biofilm formation of the strains were evaluated by the $\mathrm{OD}_{590}$; the values are reported as the mean number \pm standard deviation. Values denoted by different letters are significantly different when compared by ANOVA $(\mathrm{P}<0.05)$.

\section{Southern analysis of the wild-type strain B11 and the mutant strain B112}

Southern analysis of the wild-type strain and mutant B112 is shown in Figure 3. A single band was detected in the mutant B112 and plasmid pLOFKm (positive control), and no band was observed in the lane containing the wild-type strain B11 (negative control). This result demonstrated that only a single copy of the transposon was present in the chromosome of mutant B112.

\section{PLOFIKm Ell Bll2}

Figure 3. Southern analysis of mini-Tn10 in the wild-type strain B11 and the mutant B112. 


\section{Molecular analysis of the mutants}

The DNA sequence flanking the mini-Tn10 inserted into the mutant B112 was amplified by TAIL-PCR. Approximately 4300- and 2500-bp TAIL-PCR products were obtained following amplification of upstream and downstream sequences of the inserted transposons, respectively. These products were purified, cloned into pMD18-T, and sequenced. Sequence analysis showed that the open reading frame (ORF) inserted by miniTn10 was 3639 bp (GenBank accession No. KC165030.1) and putatively encoded a protein including 1212 deduced amino acids (Figure 4). This protein displayed the highest identity (96\%) with the MSHA pili biogenesis protein MshQ of A. aquariorum AAK1.

\section{Transmission electron micrographs}

Molecular analysis revealed that the gene $m s h Q$ of the B112 mutant was inactivated by transposon Tn10. $m s h Q$ has been shown to be a pilus-related gene linked with MSHA type IV pilus biogenesis in other bacteria (Miyazato et al., 2003; Hadi et al., 2012). Transmission electron micrographs of $A$. hydrophila wild-type B11 (Figure 5A) and the mutant B112 (Figure 5B) demonstrated that the cells of A. hydrophila wild-type B11 were surrounded by flexible pili on their surface, while the cells of mutant B112 were non-piliated, indicating that the $m s h Q$ is also required for MSHA pilus expression of $A$. hydrophila.

\section{Growth profiles}

The growth profiles of the wild-type B11 and the mutant B112 shown in Figure 6 showed that these strains exhibited very similar growth trends, suggesting that mutagenesis in the $m s h Q$ gene did not affect the growth of the mutant, and that biofilm formation deficiency of the mutant was not attributed to its growth stagnancy.

\section{Bacterial motility}

The results shown in Figure 7 demonstrate that the wild-type strain B11 and the mutant B112 were both motile in semi-soft medium, whereas the negative controls only grew along the line of inoculation, demonstrating their non-motility in semi-soft medium. This result indicates that the mutant bacteria did not lose their motility ability to seek out appropriate adhered sites after mutagenesis in the $m s h Q$ gene.

\section{Bacterial adhesion}

The adhesion ability of the wild-type B11 and the mutant B112 was determined through an adhesion assay. The results (Figure 8) showed that approximately $2.2 \times 10^{6}$ cells $/ \mathrm{cm}^{2}$ wild-type bacteria adhered to the slides, while the number of adherent bacteria of the mutant B112 was only approximately $7.1 \times 10^{4} \mathrm{cells} / \mathrm{cm}^{2}$, demonstrating that the adhesion ability of mutant B112 was significantly impaired. 


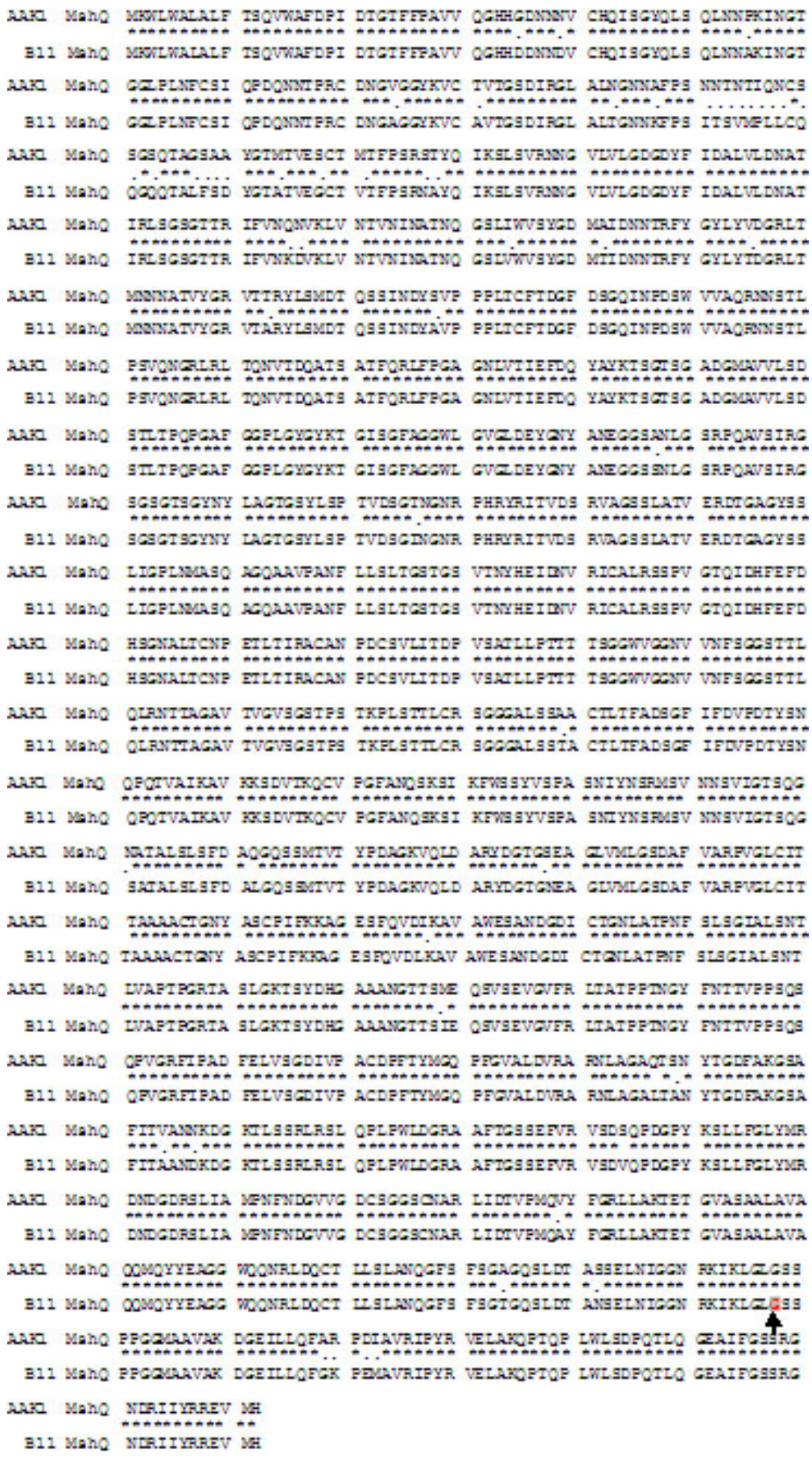

Figure 4. Comparison of the amino acid sequence of Aeromonas hydrophila. A. hydrophila B11 MshQ with the homologous MshQ of A. aquariorum AAK1. Black arrow denotes the site of Tn 10 insertion. 

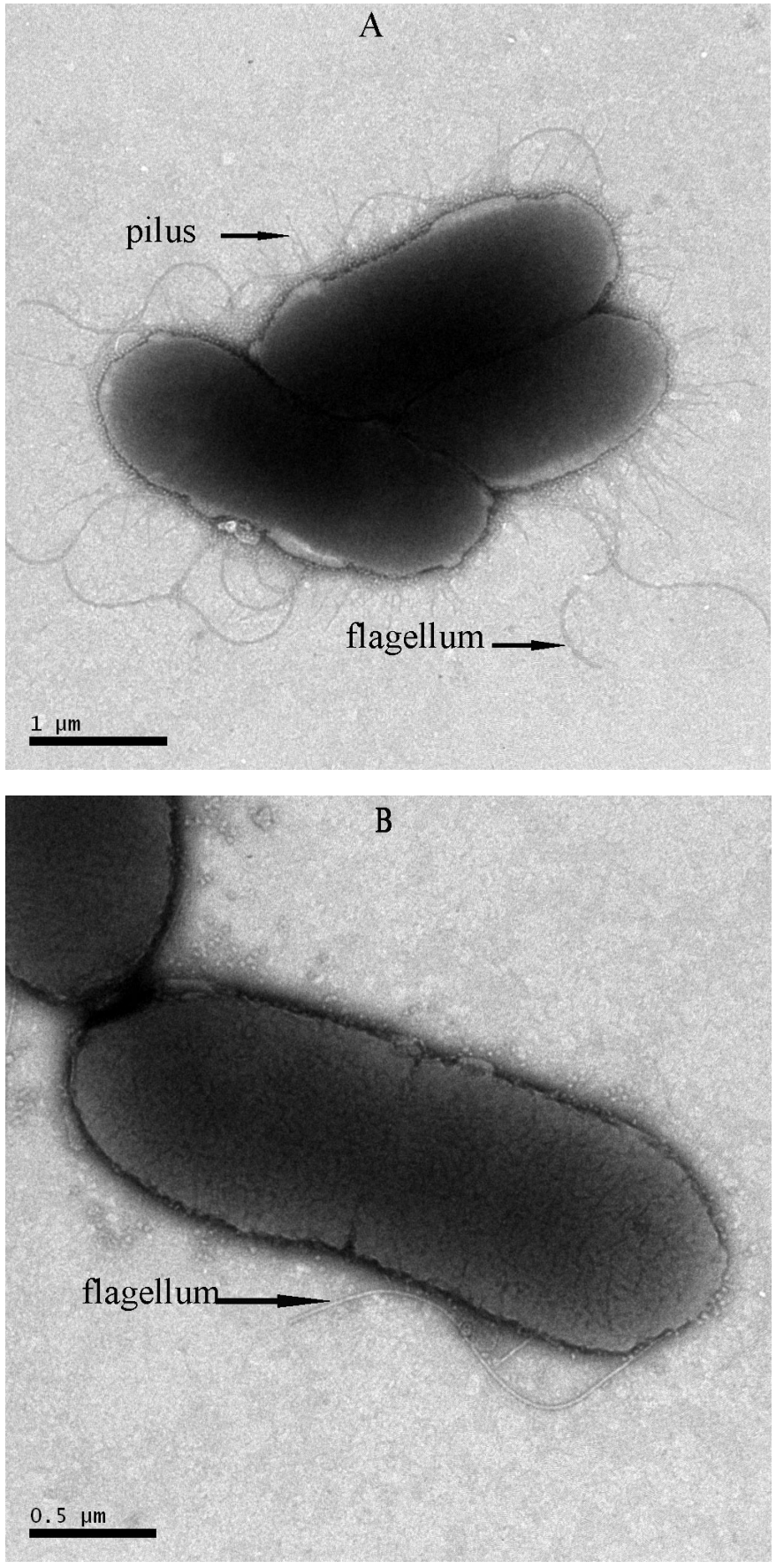

Figure 5. Transmission electron micrographs of the wild-type strains B11 and the mutant strain B112 of Aeromonas hydrophila. A. Wild-type strain B11 showing surface pili. B. Mutant B112 displaying the non-piliated phenotype. 


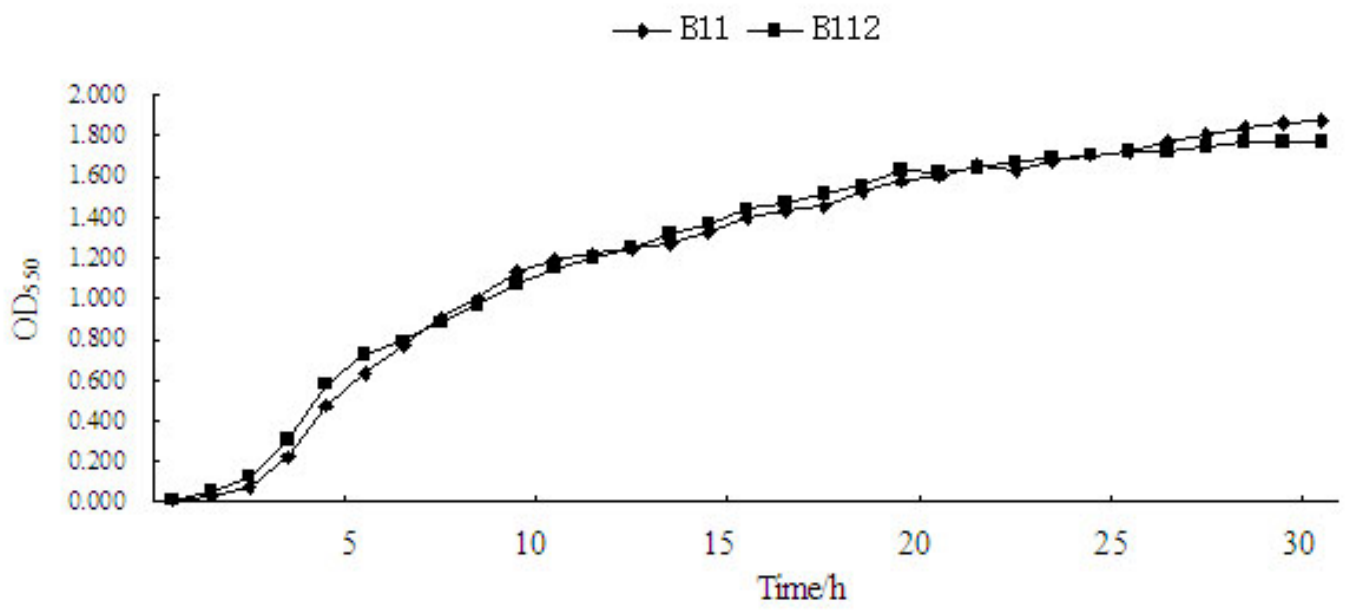

Figure 6. Growth profiles of the wild-type B11 and the mutant B112.

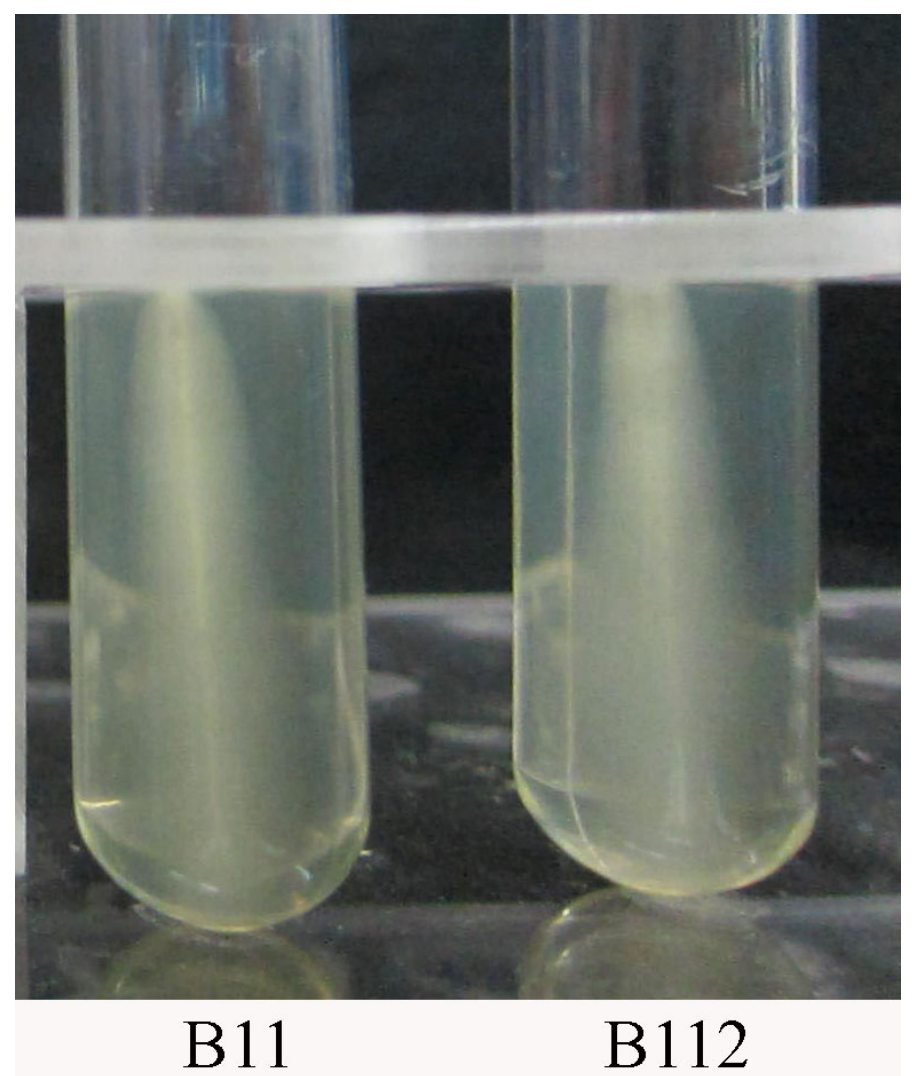

Figure 7. Motility of the wild-type B11 and the mutant B112 in semisoft medium. 


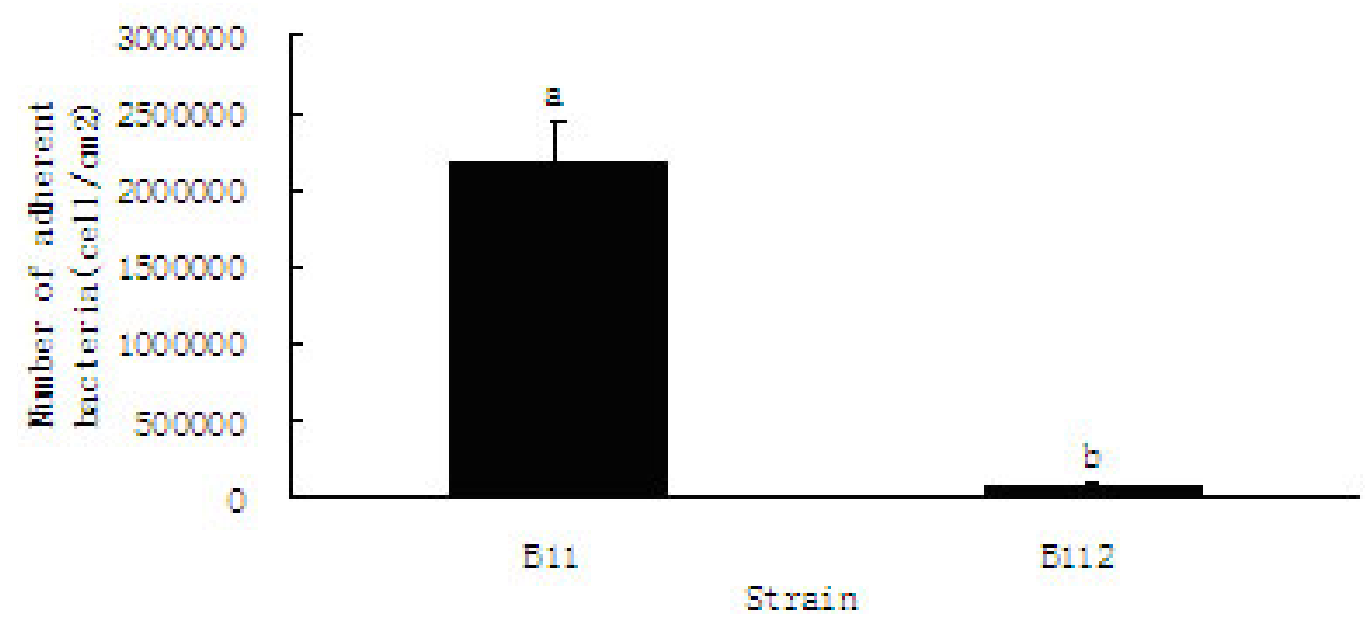

Figure 8. Bacterial adhesion. Values are reported as the mean number of bacteria adhered to the slides \pm standard deviation of adherent bacteria per $\mathrm{cm}^{2}$. Values denoted by different letters are significantly different when compared by ANOVA $(\mathrm{P}<0.01)$.

\section{DISCUSSION}

Previous studies have confirmed A. hydrophila can form biofilms (Gavín et al, 2002; Khajanchi et al., 2012). In this study, we found that $A$. hydrophila biofilm development was a dynamic process, similarly to many previously reported bacteria and Candida albicans (Donlan, 2002; Uppuluri et al., 2010). After biofilm maturation, portions of the biofilm dispersed and began another growth cycle. While numerous studies have explored the molecular mechanisms underlying the initial stages of biofilm formation and development, the events associated with biofilm dispersion have received little attention. Donlan (2002) attributed biofilm detachment to nutrient levels, quorum sensing, or flow effects. Uppuluri et al. (2010) demonstrated that $C$. albicans biofilm dispersion depends on growth conditions, including carbon source and $\mathrm{pH}$ of the media used for biofilm development. In previous studies, biofilms were typically cultured in a flow biofilm model, while in this study biofilms were cultured statically on the close wells of microtiter plate. The results showed that the development and dispersion of biofilm were alternately presented during $60 \mathrm{~h}$ continuous incubation. We speculated that biofilm detachment and dispersion were not passive behaviors of $A$. hydrophila when growth conditions deteriorated. In contrast, detachment and dispersion are voluntary activities of the bacteria. If biofilm development provides shelter and protection for bacteria against varying environmental circumstances, biofilm detachment and dispersion will facilitate the finding of new ecological niches and spread.

In this study, the mutant B112 displayed significantly adhesion and biofilm formation deficiency when compared with the wild-type strain, which may have been due to the loss of surface pili. Most bacterial pathogens have long filamentous structures known as pili or fimbriae extending from their surface. According to the morphologic characteristics, components, and functions, bacterial pili can be divided into different types. Among them, type IV pili is the most important, as it has been shown to mediate an extraordinary array of functions, including 
adhesion, motility, microcolony formation, secretion of proteases and colonization factors, and biofilm formation, among others (Shime-Hattori et al., 2006). MSHA is a member of the family of type IV pili, which had been suggested to be involved in attachment to the abiotic surface and is required for adhesion and biofilm formation in other bacteria (Watnich and Kolter, 1999; Hadi et al., 2012). Unlike other bacterial pili, which use as few as 2 proteins for assembly, type IV pilus biogenesis requires a dozen or more proteins (Scott and Zahner, 2006). Genetic and transcriptional analyses of the MSHA type IV pilus gene locus of the $V$. cholerae O1 EI Tor biotype revealed that 16 ORFs were required for MASH pilus biogenesis, these ORFs were designated $m s h$ A to $m s h \mathrm{Q}$ (Marsh and Taylor, 1999). Genetic characterization of the type IV bundle-forming pilus (Bfp) of Aeromonas veronii bv. Sobria found that a $22-\mathrm{kb}$ locus containing 17 pilus-related genes encoded the bundle-forming pilus. This locus has 2 major transcriptional units, $m s h \mathrm{I}$ to $m s h \mathrm{~F}$ and $m s h \mathrm{~B}$ to $m s h \mathrm{Q}$, and the 17 genes were similar to those in the MSAH locus of $V$. cholerae (Hadi et al., 2012).

The mshQ ORF of $V$. cholerae is the last ORF of the MSHA pilus gene locus and its product MshQ is likely to be an outer membrane protein, based on the presence of a potential signal sequence with a processing site at position 24 and the extensive predicted beta-sheet structure which occurs throughout the mature protein (Marsh and Taylor, 1999). However, the role the MshQ in MSHA biogenesis remains unclear. Genetic determinants of biofilm development of opaque (OP) and translucent (TR) V. parahaemolyticus revealed that the mshQ TR mutant failed to attach to the glass coverslip; while the mshQ OP mutant showed cell attachment, microcolony formation and 3-dimensional expansion was inhibited (Enos-Berlage et al., 2005). These results suggest that disruption of the $m s h \mathrm{Q}$ gene affects early stage of biofilm formation. Molecular analysis of the $v c f$ Q gene of $V$. cholerae strain NAGV 14 revealed that this gene encoded an orthologous protein (same functional protein) of MshQ and the deduced amino acid sequence of VcfQ showed high homology to MshQ. Mutation analysis showed that $v c f \mathrm{Q}$-deficient mutant expressed detectable levels of major pilin (VcfA), but failed to assemble them into pili, indicating that VcfQ is essential for pilus assembly (Miyazato et al., 2003). Analysis of the genome sequence of $A$. hydrophila ATCC $7966^{\mathrm{T}}$ also revealed a locus containing 17 genes encoding type IV pilus and related to MSHA of $V$. cholerae (Seshadri et al., 2006). However, there have been no reports regarding the function of MSHA pilus of $A$. hydrophila or the role of MshQ in MSHA biogenesis.

Studies of biofilm formation by several Gram-positive and Gram-negative organisms indecate that development of a mature, 3-dimensional biofilm involves the following stages: initial attachment to a solid surface, formation of microcolonies on the surface, and differentiation of microcolonies into exopolysaccharide-encased, mature biofilms (Costerton et al., 1999). Bacteria firmly adhere to biotic or abiotic surfaces as an initial step (O'Toole and Kolter, 1998). Furthermore, the planktonic cell of $V$. cholerae transiently interacted with the surface and has been observed to be mediated by MSHA pilus (Moorthy and Watnick, 2004, 2005). In this study, the $1138^{\text {th }}$ amino acid residue of MshQ of B11 was interrupted by the transposon mini-Tn10, leading to pili loss, biofilm-formation, and adhesion deficiency. However, the growth trend and motile ability of the mutant remained nearly the same as the wildtype strain. These results indicated that MshQ is also required for MSHA pili biosynthesis of A. hydrophila and MSHA pili are necessary for A. hydrophila adhesion to a substrate and initiation of biofilm development.

Studies have demonstrated that the locus contained 16 or 17 pilus-related genes encoding the MSHA pilus of $V$. cholerae or the pilus of other bacteria that are similar to MSHA 
pilus (Marsh and Taylor, 1999; Hadi et al., 2012). It had also been observed that MshA is the major pilin protein. However, mutations in each minor or major pilin gene significantly reduced the bacterium's ability to adhere and form biofilms; complementation of each mutant in trans rescued this phenotype (Hadi et al., 2012). Limited studies on MshQ revealed that it plays an important but unclear role in MSHA pili biosynthesis. In this study, we found that the MshQ protein is necessary for MSHA pili biosynthesis of A. hydrophila, and that MSHA pili play crucial roles in A. hydrophila adherence to a solid surface during early stages of biofilm formation. However, precisely how MshQ takes part in MSHA pili biosynthesis remains unclear.

\section{ACKNOWLEDGMENTS}

Research supported by the National Natural Science Foundation of China (\#31272699 and \#41176115), the National Department Public Benefit Research Foundation of China (\#200903029), and the Natural Science Foundation of Fujian Province (\#2013J01137). We gratefully acknowledge Dr. Y. Huang for providing some of the strains and plasmids used in this study.

\section{REFERENCES}

Aguilera-Arreola MG, Hernandez-Rodriguez C, Zuniga G, Figueras MJ, et al. (2005). Aeromonas hydrophila clinical and environmental ecotypes as revealed by genetic diversity and virulence genes. FEMS Microbiol. Lett. 242: 231-240.

Balebona MC, MoriNigo MA, Faris A, Krovacek K, et al. (1995). Influence of salinity and pH on the adhesion of pathogenic Vibrio strains to Sparus aurata skin mucus. Aquaculture 132: 113-120.

Cai W, De La Fuente L and Arias CR (2013). Biofilm formation by the fish pathogen Flavobacterium columnare: development and parameters affecting surface attachment. Appl. Environ. Microbiol. 79: 5633-5642.

Costerton JW, Lewandowski Z, Caldwell DE, Korber DR, et al. (1995). Microbial biofilms. Annu. Rev. Microbiol. 49: 711-745.

Costerton JW, Stewart PS and Greenberg EP (1999). Bacterial biofilms: a common cause of persistent infections. Science 284: 1318-1322.

Donlan RM (2002). Biofilms: microbial life on surfaces. Emerg. Infect. Dis. 8: 881-890.

Enos-Berlage JL, Guvener ZT, Keenan CE and McCarter LL (2005). Genetic determinants of biofilm development of opaque and translucent Vibrio parahaemolyticus. Mol. Microbiol. 55: 1160-1182.

Gavín R, Rabaan AA, Merino S, Tomas JM, et al. (2002). Lateral flagella of Aeromonas species are essential for epithelial cell adherence and biofilm formation. Mol. Microbiol. 43: 383-397.

Guo SL (2006). The Pathogenic Bacteria Identification and Correlative Immune Studies in Eels. Doctoral thesis, Institute of Hydrobiology, Chinese Academy of Sciences.

Hadi N, Yang Q, Barnett TC, Tabei SM, et al. (2012). Bundle-forming pilus locus of Aeromonas veronii bv. Sobria. Infect. Immun. 80: 1351-1360.

Hall-Stoodley L and Stoodley P (2009). Evolving concepts in biofilm infections. Cell Microbiol. 11: 1034-1043.

Herrero M, V de Lorenzo, V and Timmis KN (1990). Transposon vectors containing non-antibiotic resistance selection markers for cloning and stable chromosomal insertion of foreign genes in gram-negative bacteria. J. Bacteriol. 172: 6557-6567.

Irie Y, Borlee BR, O'Connor JR, Hill PJ, et al. (2012). Self-produced exopolysaccharide is a signal that stimulates biofilm formation in Pseudomonas aeruginosa. Proc. Natl. Acad. Sci. U. S. A. 109: 20632-20636.

Jiravanichpaisal P, Roos S, Edsman L, Liu H, et al. (2009). A highly virulent pathogen, Aeromonas hydrophila, from the freshwater crayfish Pacifastacus leniusculus. J. Invertebr. Pathol. 101: 56-66.

Karunasagar I, Otta SK and Karunasagar I (1996). Biofilm formation by Vibrio harveyi on surfaces. Aquaculture 140: 241-245.

Khajanchi BK, Kozlova EV, Sha J, Popov VL, et al. (2012). The two-component QseBC signalling system regulates in vitro and in vivo virulence of Aeromonas hydrophila. Microbiology 158: 259-271.

López D, Vlamakis H and Kolter R (2011). Biofilms. Cold Spring Harbor Laboratory Press, New York.

Marsh JW and Taylor RK (1999). Genetic and transcriptional analyses of the Vibrio cholerae mannose-sensitive 
hemagglutinin type 4 pilus gene locus. J. Bacteriol. 181: 1110-1117.

Miyazato T, Toma C, Nakasone N, Yamamoto K, et al. (2003). Molecular analysis of VcfQ protein involved in Vibrio cholerae type IV pilus biogenesis. J. Med. Microbiol. 52: 283-288.

Monds RD and O'Toole GA (2009). The developmental model of microbial biofilms: ten years of a paradigm up for review. Trends Microbiol. 17: 73-87.

Moorthy S and Watnick PI (2004). Genetic evidence that the Vibrio cholerae monolayer is a distinct stage in biofilm development. Mol. Microbiol. 52: 573-587.

Moorthy S and Watnick PI (2005). Identification of novel stage-specific genetic requirements through whole genome transcription profiling of Vibrio cholerae biofilm development. Mol. Microbiol. 57: 1623-1635.

Moscoso M, Garcia E and Lopez R (2009). Pneumococcal biofilms. Int. Microbiol. 12: 77-85.

O’Toole GA and Kolter R (1998). Initiation of biofilm formation in Pseudomonas fluorescens WCS365 proceeds via multiple, convergent signalling pathways: a genetic analysis. Mol. Microbiol. 28: 449-461.

Ojha AK, Baughn AD, Sambandan D, Hsu T, et al. (2008). Growth of Mycobacterium tuberculosis biofilms containing free mycolic acids and harbouring drug-tolerant bacteria. Mol. Microbiol. 69: 164-174.

Ringø E, Løvmo L, Kristiansen M, Bakken Y, et al. (2010). Lactic acid bacteria vs. pathogens in the gastrointestinal tract of fish: a review. Aquaculture Res. 41: 451-467.

Rock JL and Nelson DR (2006). Identification and characterization of a hemolysin gene cluster in Vibrio anguillarum. Infect. Immun. 74: 2777-2786.

Saville RM, Dieckmann N and Spormann AM (2010). Spatiotemporal activity of the mshA gene system in Shewanella oneidensis MR-1 biofilms. FEMS Microbiol. Lett. 308: 76-83.

Schwartz K, Syed AK, Stephenson RE, Rickard AH, et al. (2012). Functional amyloids composed of phenol soluble modulins stabilize Staphylococcus aureus biofilms. PLoS Pathog. 8: e1002744.

Scott JR and Zahner D (2006). Pili with strong attachments: Gram-positive bacteria do it differently. Mol. Microbiol. 62: 320-330.

Seshadri R, Joseph SW, Chopra AK, Sha J, et al. (2006). Genome sequence of Aeromonas hydrophila ATCC 7966T: jack of all trades. J. Bacteriol. 188: 8272-8282.

Shime-Hattori A, Iida T, Arita M, Park KS, et al. (2006). Two type IV pili of Vibrio parahaemolyticus play different roles in biofilm formation. FEMS Microbiol. Lett. 264: 89-97.

Uppuluri P, Chaturvedi AK, Srinivasan A, Banerjee M, et al. (2010). Dispersion as an important step in the Candida albicans biofilm developmental cycle. PLoS Pathog. 6: e1000828.

van der Marel M, Schroers V, Neuhaus H and Steinhagen D (2008). Chemotaxis towards, adhesion to, and growth in carp gut mucus of two Aeromonas hydrophila strains with different pathogenicity for common carp, Cyprinus carpio L. J. Fish Dis. 31: 321-330.

Vine NG, Leukes WD and Kaiser H (2004). In vitro growth characteristics of five candidate aquaculture probiotics and two fish pathogens grown in fish intestinal mucus. FEMS Microbiol. Lett. 231: 145-152.

Watnick PI and Kolter R (1999). Steps in the development of a Vibrio cholerae El Tor biofilm. Mol. Microbiol. 34: 586-595. 